\title{
The Effect of Flipped Classroom Instruction on Appropriacy of English Apology by Thai EFL Learners
}

\author{
Katchamat, $\mathbf{P}^{1}$ \\ ${ }^{1}$ Department of English, Faculty of Humanities and Social Sciences, \\ Thepsatri Rajabhat University, Lop Buri, Thailand \\ Corresponding email: esperando@hotmail.co.th
}

\begin{abstract}
Pragmatic competence plays a crucial role in EFL learners' communicative competence. In order to communicate successfully and appropriately, the effective potential of using pragmatic competence cannot be disregarded. A number of studies have aimed to investigate its production, but how EFL learners acquire and use those production appropriately has not been fully explored. To fulfill this gap, this research article attempted to investigate the effect of the flipped classroom on pragmatic development focused on apology strategies. The participants were 22 English-major students in their third and fourth year of study. The study made use of an experimental design in which the participants were homogenized and taught by the flipped classroom instruction. The data collection was done by using a Discourse Completion Test (DCT) as pre-test and post-test. The findings revealed that the frequency of use in some categories of apology speech act set significantly differed between the two groups, but the overall number of frequency was not significantly different. In addition, the result from the paired sample t-test of the pre-test and post-test showed that the learners who were taught by the flipped classroom instruction used English apology more appropriate and accurate than the pre-test.
\end{abstract}

Keywords: apology strategies; discourse completion test; flipped classroom instruction

DOI: $10.20961 /$ ijpte.v\%vi\%i.25142 


\section{INTRODUCTION}

The switch from grammatical to communicative competence in language learning has much reinforced by educators and teachers. Therefore, recent researchers' interest towards sociolinguistics has gained more awareness. However, it is not adequate to stop students' language learning skills at superficial English language abilities, but pragmatic competence is essential and should have not been disregarded. Kasper (1997) describes pragmatic competence as knowledge of communicative action in which sociocultural contexts are linked with meanings in real life communication. The interlocutor is responsible for interpreting intended message. Also, how to carry it out and the ability to carry out language appropriately according to contextual factor and sociolinguistic variation are required.

Unfortunately teaching pragmatic competence as socio-cultural skills is not adequately emphasized in teaching and learning in Thailand. For this reason, Thai EFL learners often fail to recognize the correct function of speech acts in EFL educational settings. One of the problems is that the learners were passive because teachers spent most of the time lecturing and assigning some exercises and worksheets to individual students. Real-life communication in English and knowing how to use particular pragmatic competence strategies to express simultaneously with communicative competence are needed. Furthermore, the learners are in the middle of the $21^{\text {st }}$ century teaching and learning where the technological advancements are further recommended for them. The additional use of multimedia technology is essential and facilitative tools for second language pedagogy.

Moreover, pragmatic competence is considered as cultural specific (Kachru, 1998). The EFL learners who have an inadequate skill of pragmatic competence are likely unsuccessful in communicative goal because only linguistic competence does not guide the learners to be as 'fluent users' if they are still unable to produce language socially and culturally (Bardovi-Harlig and Hartford 1991; Fraser, 2010). The learners tend to translate their mother tongue into second language without considering specific cultural norms. For solving the problems, helping them learn the appropriate techniques by applying comprehensive teaching methodologies is considered to be an indispensable part of any EFL teaching environment. However, recent researchers have questioned how and what to teach pragmatics effectively. Some studies have answered some gaps of this problem, for instance, many studies applied the explicit and implicit instruction (House \& Kasper, 1981; House, 1996; Tateyama et al., 1997) to enhance EFL learners' pragmatic competence, but using different teaching techniques are still required.

In this study, the researcher made use of the flipped classroom to accomplish the goal. The flipped classroom is designed to defame traditional lectures encouraging of flexible and dynamic exercises in class and multimedia technology for class and home use. The class is emphasized on practical application and discussion, rather than memorization (Bergmann \& Sams, 2012). In line with Kasper's (1997) notion that the students need to learn and assess native speaker's pragmalinguistic usage of language by themselves because learning through traditional teacher- 
based approach is not enough even though the mother tongue of the students may share some characteristics to second language.

Furthermore, Kasper \& Dahl (1991) state that pragmatic competence is the ability to comprehend and produce speech acts for different purposes such as greeting, thanking, refusing, apologizing and so on. To be more specific, the researcher employed the speech act of apology as a case study of learners' pragmatic competence development. The apology strategies vary cross-linguistically across culture and are frequently used in human life (Salehi, 2014). Besides, it is considered to be as remedial interchanges in which human attempts to apologize and seek for forgiveness when interlocutor's social harmony and norm are violated (Olshtain \& Cohen, 1983). According to the above fact, it would be a communication breakdown among Thai EFL learners when they are demanded to apologize to an English native speaker, but cannot perform the strategies socially and appropriately. Since a language is always connected with its culture, it is crucial to teach the learners to pragmatically use the correct form of each situation.

In teaching pragmatic competence, many studies have been investigating mostly on the effect of explicit and implicit instruction to develop students' pragmatic competence as mentioned earlier. However, none of the studies focused on the effect of flipped classroom instruction. It is still questionable whether or not the flipped classroom instruction can develop students' appropriateness and usage of apology strategies.

The main purpose of the present study was aimed at examining the teaching effect of flipped classroom approach whether or not the treatment improves the appropriate use of apology strategies among students. Based on the purpose of the study, the following research questions are proposed as following: 1.) What are the apology strategies used by the students before and after teaching with the flipped classroom approach? 2.) Are there any significant differences among apology strategies used by the students before and after teaching with the flipped classroom approach? 3.)Does the flipped classroom approach improve the students' appropriate use of apology strategies?

\section{CONCEPTUAL FRAMEWORK}

This present study made use of the flipped classroom instruction introduced by Sams and Bergmann (2012) who were recognized as the pioneers. The idea of the instruction basically aims at adapting some digital technology into learners' environment that is well-suited for home use. Moreover, apology speech act speech proposed by Olshtain \& Cohen (1983) and Blum-Kulka, House \& Kasper (1989) was employed as a conceptual framework as well, since it has been referred as a conceptual framework by many research studies published on the field.

\section{METHOD}

A group of 22 fourth and third-year students, majoring in English participated voluntarily. For the students' English knowledge background, the fourth-year students enrolled the Business English course and the third-year students enrolled 
the Discourse Approach in Reading and Text Interpretation course of the first semester, 2017 academic year at Thepsatri Rajabhat University. These students had no experience of studying or traveling abroad. To make sure that the students' English proficiency in terms of skills was consistently relevant, the Cambridge Placement Test with the equivalent scale of the Common European Framework of Reference (CEFR) were distributed to the students and the students were selected based on their results which were B1, equivalent to pre-intermediate.

The research instruments used in the study were divided into two main categories as follows:

The study employed a Discourse Completion Test (DCT) from Thijittang (2010) as pre-test and post-test. It was a modified version of Olshtain \& Cohen (1983), Cohen, Olshtain, \& Rosenstein (1986), Bergman \& Kasper (1993). The benefits of DCT were that it can quickly gather large amounts of data in a short time and easily allows the researchers to statistically compare the strategies used by the participants (Beebe \& Cummings, 1996). The ten realistic situations in the DCT were based on an apology sociolinguistic variation which was social status, social distance and severity of offense. The DCT included of situational description items which required students to read and write their response into the given space as if they would say verbally to English native speaker, regardless of psychological expression; participants' gesture, voice or facial expression since these were not relevant to the objectives.

To make sure that the DCT was valid, the researchers sent a paper version of the DCT to two native speakers of English, American and British and one Thai doctoral holder of English studies to evaluate its feasibilities including, comprehensibility, effectiveness and validity of the DCT by using the index of Item Objective Congruence (IOC) (Rovinelli \& Hambleton, 1976). After that, the researchers revised the DCT based on the feedback from the experts until reached a final consensus. In the final stage, the DCT was pilot-tested with 10 first-year English education major students to determine a time of completion and fine-tune an unexpected problem.

For the Flipped Classroom Approach, the lessons were listed as follows:

1. Before Class

1.1. The students watching the online videos about various apology situations in websites on internet in order to find any usage of English apology.

1.2. The students comparing the English apology strategies to Thai apology strategies based on assigned socio-linguistics variations.

1.3. The students going over of what they've learned by themselves and preparing for the class presentation.

2. In-class

2.1. Introduction by the lecturer

2.2. The students presenting of what they've learned to the class.

2.3. The lecturer, American native speaker and students discussing and questioning friends' presentation.

2.4. The lecturer and students summarizing today's lesson.

3. After-class 
3.1. The students videotaping themselves a role play and submitting to the lecturer.

For the data collection, the DCT was distributed to the participants before and after the implementation of the flipped classroom. Before that, the researcher explained the rationale, objectives, and procedures to the participants. Without any inquiries returned, the participants did the tests. There were 30 minutes given to the participants to complete the DCT. Throughout the test, the participants were not allowed to look up words in their dictionary, and mobile phone.

To categorize the students' apology strategies, the obtained data were sent to two coders, a native speaker of English and the first author, to encode and classify the responses into apology strategies classified by Olshtain \& Cohen (1983) and Blum-Kulka, House \& Kasper (1989). They were grouped into six major components with nine sub-categories as follows:

1. Illocutionary force indicating devices (IFIDs) (e.g. "I'm sorry" "I apologize" "Forgive me")

2. Explanation of account (e.g. "The traffic was terrible.")

3. Taking on responsibility

3.1. Explicit self-blame (e.g. "It is my mistake.")

3.2. Lack on intent (e.g. "I didn't mean it.")

3.3. Expression of self-deficiency (e.g. "I was confused.")

3.4. Expression of embarrassment (e.g. "I feel awful about it.")

3.5. Self-dispraise (e.g. "I'm such a dimwit.")

3.6. Justify hearer (e.g. "You're right to be angry.")

3.7. Refusal to acknowledge guilt

3.7.1. Denial of responsibility (e.g. "It wasn't my fault.")

3.7.2. Blame the hearer (e.g. "It's your own fault.")

3.7.3. Pretend to be offended (e.g. "I'm the one to be offended.")

4. Concern for the hearer (e.g. "Are you all right?)

5. Offer of repair (e.g. "I'll pay for the damage.")

6. Promise of forbearance (e.g. "It won't happen again.")

The participants' responses were coded as the following example below:

Situation: Speaker damaged a friends' camera

You will be saying: I'm sorry. It is my fault. I'll buy a new one for you tomorrow. From the above response, it was analyzed into 3 units and coded as a semantic formula as follows:

1. I'm sorry = coded as 'Illocutionary force indicating devices (IFIDs)'

2. It my fault $=$ coded as 'Explicit self-blame'

3. I'll buy a new one for you tomorrow = coded as 'Offer of repair'

For validity and reliability of data analysis of the categorization of the apology strategies, it was stipulated that the results from the two coders must agree in consensus. If there was a disagreement in categorization, discussions between the two coders were done until a final decision was made. After that, descriptive statistics, i.e., frequencies and percentages, and an independent sample t-test were used to find the similarities and differences between responses of participants in the two groups. 
After the participants' apology strategies were categorized, the responses from the DCT were rated according to the four aspects of language appropriacy of Hudson et al. (1992, 1995) and Hudson (2001). The language appropriacy aspects contain correct expression, quality of information, strategies choices, and level of formality. The each of appropriacy aspects of the participants' responses was marked by 5 analytic scales of Likert. The scales refer to ' 5 for completely appropriate', ' 4 for mostly appropriate' ' 3 for generally appropriate', ' 2 for not very appropriate but acceptable', and ' 1 for not appropriate and not acceptable'. The overall score was the mean scores of the four aspects. For example, if the rater marks $4+4+5+5$ in the question that means the all overall of the score was 4.5. The full score for each item was 5 and there were 10 items so that the total scores from the DCT was 50.

The two raters was American English native speakers who were trained to rate participants' responses. Also, the scores from the raters were confirmed by the Pearson correlation in order to maintain the reliability.

\section{RESULT}

In order to answer the first and second research questions, the participants' apology responses were categorized in to its strategies. The results were as follows:

Table 1 The comparison of the apology strategies used of the participants before and after the implementation

\begin{tabular}{|c|c|c|c|c|}
\hline No & Apology Strategies & $\begin{array}{r}\text { Pre-test } \\
(\mathrm{F}, \%)\end{array}$ & $\begin{array}{c}\text { Post-test } \\
\text { (F, \%) }\end{array}$ & $\begin{array}{c}\text { P-Value } \\
\text { (Sig.) } \\
\text { 2-tailed }\end{array}$ \\
\hline 1 & $\begin{array}{l}\text { Illocutionary force indicating } \\
\text { devices (IFIDs) }\end{array}$ & $385(54.61)$ & $\begin{array}{c}316 \\
(41.63) \\
\end{array}$ & .000 \\
\hline 2 & Explanation of account & $94(13.33)$ & $\begin{array}{c}115 \\
(15.15)\end{array}$ & .173 \\
\hline 3 & Explicit self-blame & $74(10.50)$ & $58(7.64)$ & .336 \\
\hline 4 & Offer of repair & $59(8.37)$ & $75(9.88)$ & .195 \\
\hline 5 & Expression of self-deficiency & $34(4.82)$ & $51(6.72)$ & .059 \\
\hline 6 & Promise of forbearance & $24(3.40)$ & $40(5.27)$ & .049 \\
\hline 7 & Concern for the hearer & $18(2.55)$ & $28(3.69)$ & .172 \\
\hline 8 & Lack on intent & $16(2.27)$ & $42(5.53)$ & .031 \\
\hline 9 & Justify the hearer & $1(0.14)$ & $7(0.92)$ & .044 \\
\hline 10 & Expression of embarrassment & 0 & $13(1.71)$ & .034 \\
\hline 11 & Self-dispraise & 0 & $9(1.19)$ & .001 \\
\hline 12 & Denial of responsibility & 0 & $2(0.26)$ & .162 \\
\hline 13 & Blame the hearer & 0 & $3(0.40)$ & .186 \\
\hline \multirow[t]{2}{*}{14} & Pretend to be offended & 0 & 0 & 0 \\
\hline & $\begin{array}{l}\text { Total and significant value of } \\
\text { all strategies }\end{array}$ & $705(100)$ & $759(100)$ & 0.731 \\
\hline
\end{tabular}

As the Table 1 presented above, the table revealed the participants' apology strategies elicited from the pre-test and post-test. The results showed that both 
periods used different apology strategies and different number of frequency. From the pre-test, the participants used the apology strategies for a total number of 705 times, whereas they made a total number of 759 times in the post-test. In the pretest period, the participants employed only 9 out of 14 strategies available from the framework, but they frequently employed more strategies in the post-test, only 'Pretend to be offended' was not used either from both period. However, the frequency of 'IFIDs' and 'Explicit self-blame' from the pre-test was higher than the post-test. There were statistically significant differences between the two periods in the use of 'Illocutionary force indicating devices (IFIDs)', 'Promise of forbearance', 'Lack on intent', 'Justify the hearer', 'Expression of embarrassment', and 'Self-dispraise', but there was no statistically significant difference in the overall.

\section{The Comparison of Apology Responses Based on Four Language Appropriacy Aspects}

In order to answer the third research question, the participants' English apology responses in relation to the four language appropriacy aspects from Hudson et al. (1992, 1995) and Hudson (2001), namely correction expressions, quality of information, level of formality and strategies choices, was analyzed from their scores in the pre-test and post-test. In the table, the results were separately presented by the aspects.

Table 2 The comparison of four language appropriacy aspects from the pre-test and post-test

\begin{tabular}{|c|c|c|c|c|c|c|}
\hline Appropriacy & Test & Mean & S.D. & $\begin{array}{c}\text { Mean } \\
\text { Difference } \\
\end{array}$ & $\mathbf{t}$ & $\begin{array}{l}\text { Sig. }(2 \\
\text { tailed })\end{array}$ \\
\hline \multirow[t]{2}{*}{$\begin{array}{l}\text { Correction } \\
\text { Expressions }\end{array}$} & $\begin{array}{l}\text { Pre- } \\
\text { test }\end{array}$ & 27.15 & 1.69 & \multirow{2}{*}{8.57} & \multirow{2}{*}{-12.09} & \multirow{2}{*}{.000} \\
\hline & $\begin{array}{c}\text { Post- } \\
\text { test }\end{array}$ & 35.72 & 2.96 & & & \\
\hline \multirow[t]{2}{*}{$\begin{array}{l}\text { Quality of } \\
\text { Information }\end{array}$} & $\begin{array}{l}\text { Pre- } \\
\text { test }\end{array}$ & 28.09 & 2.28 & \multirow{2}{*}{10.45} & \multirow{2}{*}{-11.19} & \multirow{2}{*}{.000} \\
\hline & $\begin{array}{c}\text { Post- } \\
\text { test }\end{array}$ & 38.54 & 2.58 & & & \\
\hline \multirow[t]{2}{*}{$\begin{array}{l}\text { Level } \\
\text { Formality }\end{array}$} & $\begin{array}{l}\text { Pre- } \\
\text { test }\end{array}$ & 27.81 & 2.68 & \multirow{2}{*}{8.31} & \multirow{2}{*}{11.87} & \multirow{2}{*}{.000} \\
\hline & $\begin{array}{c}\text { Post- } \\
\text { test }\end{array}$ & 36.12 & 1.51 & & & \\
\hline \multirow[t]{2}{*}{$\begin{array}{l}\text { Strategies } \\
\text { Choices }\end{array}$} & $\begin{array}{l}\text { Pre- } \\
\text { test }\end{array}$ & 29.36 & 1.91 & \multirow{2}{*}{6.73} & \multirow{2}{*}{-12.03} & \multirow{2}{*}{.000} \\
\hline & $\begin{array}{c}\text { Post- } \\
\text { test }\end{array}$ & 36.09 & 1.47 & & & \\
\hline
\end{tabular}


From the table presented above, the mean scores from the pre-test were lower than the post-test. The participants' English apology appropriacy in all aspects was significantly improved at the level of .01. In terms of mean different, the highest improvement of the participants was quality of information (10.45). The second one was correction expressions (8.57) and the third one was level of formality (8.31). The strategies choices ranked at the lowest aspect (6.73).

Table 3 The comparison of overall participants scores from pre-test and post-test

\begin{tabular}{|c|c|c|c|c|c|c|c|}
\hline \multirow{3}{*}{$\begin{array}{l}\mathbf{N} \\
22\end{array}$} & \multicolumn{2}{|c|}{ Pre-test } & \multicolumn{2}{|c|}{ Post-test } & \multirow{2}{*}{$\mathbf{t}$} & \multirow{2}{*}{$\begin{array}{c}\text { Mean } \\
\text { Difference }\end{array}$} & \multirow{2}{*}{$\begin{array}{l}\text { Sig. }(2 \\
\text { tailed) }\end{array}$} \\
\hline & $\bar{X}$ & S.D. & $\bar{X}$ & S.D. & & & \\
\hline & 28.09 & 1.66 & 36.45 & 1.30 & -16.28 & 8.36 & .000 \\
\hline
\end{tabular}

According to the Table 3 . The mean scores of four aspects were computed using paired sample t-test. There was a statistically significant improved at the level of .01 level. This indicated that the implementation of the flipped classroom instruction can improve the participants' appropriacy of English apology.

\section{DISCUSSIONS}

In this study, the results revealed that the post-test period provided a lager number of apologies and more strategy selection than the pre-test period. Generally, the number of apology strategies and selection was widened in accordance with learners' increasing English proficiency (Istifci \& Kampusu, 2009; Rastegar \& Yasami, 2014). In the same way, the results from this study indicated that participants' responses were broadened after the implementation of flipped classroom instruction, only the 'IFIDs' and 'Explicit self-blame' were reduced in a total frequency. According to Olshtain \& Cohen (1983), 'IFIDs' is a starter and overwhelming strategy combined with other strategies. In the results, 'IFIDs seemed to be discrepant and redundant of the usage in the pre-test. After examining the responses from the pre-test closely, the 'IFIDs' was redundant because the participants employed it in many positions in the sentence. For example, one of the participants responded as 'I'm so sorry. I didn't look at my way. Sorry again'. The lacking of sociolinguistic constraint awareness which were social status, social distance and severity of offense also influenced the selection of 'IFIDs'. For instance, in the situation of 'a boss was 30 minutes late for meeting', all of the participants in the pre-test period employed 'IFIDs' as a starter in their responses, but some of them in the post-test omitted the 'IFIDs' because they felt that they were at higher social status and the situation was not too severe. The participants' sociolinguistic constraint awareness were gained in the in-class session where the lecturer and an American native speaker and friends discussed and questioned their friend's presentation. This finding can be indicated that the implementation facilitated the participants in sociolinguistic constraint awareness as well.

Notwithstanding, the participants in the post-test performed 13 strategies available in the speech act set, which was higher than the pre-test (9 strategies), only 
'Pretend to be offended' was not used in either groups. One of the possible reasons for the difference was that the participants acquired a second language pragmatic competence by watching the films and video clips about various apology situations on internet. The lengths of exposure to the discussion and question session with their friends who already gathered the knowledge of how to apologize and comparing between Thai and English apology before the class gave them a cross-cultural awareness to use apology appropriately and accurately. In addition, the lengths of exposure to more time and space to prepare and understand individually provided them "the greater gains in conceptual understanding" (Berrett, 2012).

According to Table 2, the participants' English apology appropriacy in each of four aspects was significantly improved at the level of .01. Moreover, the overall participants' scores from pre-test and post-test were also significantly improved at the level of .01 as presented in Table 3. The highest improvement of the participants was quality of information. These aspects refer to the amount of information. The participants from the pre-test employed less strategies than the post-test because they employed a direct utterance which was very shorter than the native speaker. Some sentence was derived from their first language. For example, in the situation of 'damaging a friend's camera', some participants response as 'I'm sorry, Are you angry me?. This kind of question was derived from Thai common apology 'Krot Mai A' which is asking the recipient not to be angry. The second improvement was correction expressions which refer to those who employed an appropriate expression without no grammatical errors. At first, the participants faced the grammatical errors which were the main problem of most Thai EFL learners. After the implementation, they did better at the post-test. In addition, the level of formality was ranked at the third. This refers to the degree of formal or informal sentence and politeness. There was an improvement of the level of formality at the post-test. This specific aspect was complicated for the participants because it was inevitably involved with some cultural differences and uncertainties as Wierzbicka (1985) stated that "speech acts are culturalspecific communicative routines". This problem was solved by providing them a chance to compare the differences between Thai and English apology, then their in-class discussion was checked by the native speaker including a cross-cultural compromise in language. For the lowest rank, the strategies choices refer to those who employed the strategies provided in the lessons. In the pre-test, most of the participants tended to use the apologetic formulae in accordance with their mother tough. After the implementation, the choices made were improved.

\section{CONCLUSIONS}

The purposes of the present study were to investigate the effects of the flipped classroom instruction on appropriacy of English apology and to examine the apology strategies used by the students'. In sum, more apology strategies were frequently used in the post-test. Also, the study demonstrated that the students' appropriacy of English apology was significantly improved based on the four language appropriacy aspects. The results indicated that teaching pragmatic competence should not be focused on only lecturing in front of the class, but 
adequate self-learning, presentation, discussion, and question which build interactive environments are required for the language classroom.

\section{ACKNOWLEDGMENTS}

The author would like to express my gratitude to the Faculty of Humanities and Social Sciences, Thepsatri Rajahbat University, Thailand, which financially sponsored this research.

\section{REFERENCES}

Bardovi-Harlig, K., \& Hartford, B.S. (1991). Saying "No" in English: Native and nonnative rejection. Pragmatics and Language Learning, Vol.7, monograph series Vol.2. Urbana-Campaign: Division of English as an International Language, University of Illinois, Urbana-Campaign.

Beebe, L. M. \& Cummings, M.C. (1996). "Natural speech act versus written questionnaire data: How data collection method affects speech act performance". In S.M. Gass and J. Neu (Eds.). Speech Acts across Cultures (pp. 65-86).

Bergman, M. L., \& Kasper, G. (1993). Perception and Performance in Native and Nonnative Apology. In G. Kasper \& S. Blum-Kulka (Eds.), Interlanguage Pragmatics (pp. 82-107). Oxford: Oxford University Press.

Bergmann, J., \& Sams, A. (2012). Flip your classroom: Reach every student in every class every day. International Society for Technology in Education.

Berrett, D. (2012). How 'flipping' the classroom can improve the traditional lecture. The Education Digest, 78(1), 36.

Blum-Kulka, S., House, J., \& Kasper, G. (1989). Cross-cultural pragmatics: Requests and apologies. Norwood, NJ :Ablex Pub.

Cohen, A., Olshtain, E., \& Rosenstein, D. S. (1986). Advanced EFL apologies: what remains to be learned? International Journal of Second Language, 62, $51-74$.

Fraser, B. (2010). Pragmatic Competence: The case of Hedging. In G. Kaltenböck, W. Mihatsch, \& S. Schneider. (Eds.) New approaches to hedging. Bingley, UK: Emerald.

House, J. (1996). Developing pragmatic fluency in English as a foreign language: Routines and metapragmatic awareness. Studies in Second Language Acquisition, 18, 225-252.

House, J., \& Kasper, G. (1981). Politeness markers in English and German. In F. Coulmas, (Ed.), Conversational Routine: Explorations in Standardized Communication Situations and Prepatterned Speech (pp. 157-185). New York: Mouton de Gruyter.

Hudson, J. (2001). Indicators for Pragmatic Instruction: some quantitative tools. In K. R. Rose \& G. Kasper (Eds.), Pragmatics in language teaching (p. 283300). $\quad$ Cambridge, UK: Cambridge University Press. 
Hudson, J., Detmer, E. \& Brown, J.D. (1992). A framework for testing crosscultural pragmatics. Honolulu: Second Language Teaching \& Curriculum Center, University of Hawai'i at Manoa.

Hudson, J., Detmer, E. \& Brown, J.D. (1995). Developing prototypic measures of cross-cultural pragmatics. Honolulu: Second Language Teaching \& Curriculum Center, University of Hawai'i at Manoa.

Istifci, I. \& Kampusu, Y. (2009). The Use of Apologies by EFL Learners. English Language Teaching, 2(3), 15-25.

Kachru, Y. (1998). Culture and speech acts: Evidence from Indian and Singaporean English. Studies in the Linguistic Sciences, 28(1), 79-98.

Kasper, g. \& Dahl, M. (1991). Research Methods in Interlanguage Pragmatics. SSLA, 13, 215-247.

Kasper, G. (1997). Can Pragmatic Competence be Taught? Retrieved June 26, 2015, from http://nflrc.hawaii.edu/networks/NW06/default.html

Olshtain, E. \& Cohen, A. D. (1983). Apology: A speech act set. In N. Wolfson \& E. Judd (Eds.), Sociolinguistics and language acquisition (pp. 18-35). Rowley, MA: Newbury House.

Rastegar, S., \& Yasami, F. (2014). Iranian EFL Learners' Proficiency Levels and Their Use of Apology Strategies. International Conference on Current Trends in ELT, 1535-1540.

Rovinelli, R. J., \& Hambleton, R. K. (1976). On the Use of Content Specialists in the Assessment of Criterion Referenced Test Item Validity. ERIC, 37.

Salehi, R. (2014). A Comparative Analysis of Apology Strategy: Iranian EFL Learners and Native English Speakers. Social and Behavioral Science: International Conference on Current Trends in ELT, 98, 1658-1665.

Tateyama, Y., Kasper, G., Mui, L., Tay, H., \& Thananart, O., (1997). Explicit and implicit teaching of pragmatics routines. In L. Bouton (Ed.), Pragmatics and language learning, Vol. 8. Urbana, IL: University of Illinois at UrbanaChampaign.

Thijittang, S. (2010). A Study of Pragmatic Strategies of English of Thai University Students: Apology Speech Acts. Ph.D. Thesis. University of Tasmania: Australia.

Wierzbicka, A. (1985). "Different cultures, different languages, different speech acts: Polish vs. English.” Journal of Pragmatics 9, 145-178. 
